\title{
A formação de conceitos científicos e a ressubordinação da memória: ressignificando práticas docentes
}

\author{
The formation of scientific concepts and the resubordination of memory: giving \\ new meaning to teaching practices
}

\author{
Solange de Castro \\ Mestrado em Educação/UNIOESTE \\ Universidade Estadual do Oeste do Paraná/UNIOESTE \\ Cascavel, Paraná - Brasil \\ solangecastro@escola.pr.org.br \\ Elisabeth Rossetto \\ Doutorado em Educação/UFRG \\ Universidade Estadual do Oeste do Paraná/UNIOESTE \\ Cascavel, Paraná - Brasil \\ erossetto2013@gmail.com
}

\begin{abstract}
Resumo: Este estudo discute a formação dos conceitos científicos e o desenvolvimento da memória de alunos entre a primeira infância e a adolescência. Caracteriza-se como teórico/bibliográfico, pautado na Psicologia Histórico-Cultural, e documental, com ênfase no Referencial Curricular do Paraná (2018). O currículo escolar, como tem se desenhado na legislação vigente, não ampara a prática docente. O Referencial Curricular do Paraná, que orienta a Educação Infantil e o Ensino Fundamental desde o início de 2020, não demonstra preocupação no sentido de aproximar teoria e prática, fragilizase teoricamente ao não relacionar estreitamente os pressupostos epistemológicos com o trabalho em sala de aula. Assim, nesse contexto, considera-se que a formação continuada dos professores proposta pelo Paraná não tem contribuído para a formação dos conceitos científicos e o desenvolvimento da memória de alunos da educação básica.
\end{abstract}

Palavras chave: psicologia histórico-cultural; formação de conceitos científicos; desenvolvimento da memória

Abstract: This article discusses the formation of scientific concepts and the development of memory in students between early childhood and adolescence. It is characterized as theoretical/bibliographical, based on the Cultural-Historical Psychology, and documental, with emphasis on the Curriculum Reference of Paraná (2018). The school curriculum, as it has been designed in the current legislation, does not support the teaching practice. The Paraná Curricular Reference, which guides Kindergarten and Elementary School since the beginning of 2020, does not show concern in bringing theory and practice together, it is theoretically weakened by not closely relating the epistemological assumptions with the work in the classroom. Thus, in this context, it is considered that the continuing education of teachers proposed by Paraná has not contributed to the formation of scientific concepts and the development of memory of basic education students.

Keywords: cultural-historical psychology; scientific concept formation; memory development.

Cite como

(ABNT NBR 6023:2018)

ROSSETTO, Elisabeth; CASTRO, Solange. A formação de conceitos científicos e a ressubordinação da memória: ressignificando práticas docentes. Dialogia, São Paulo, n. 40, p. 1-20, e20617, jan./abr. 2022. Disponível em: https://doi.org/10.5585/40.2022.20617.

American Psychological Association (APA)

Rossetto, E., \& Castro, S. (2022, jan./abr.) A formação de conceitos científicos e a ressubordinação da memória: ressignificando práticas docentes. Dialogia, São Paulo, 40, p. 1-20, e20617. https://doi.org/10.5585/40.2022.20617. 


\section{Introdução}

Este artigo é resultado de um estudo teórico/bibliográfico e documental, que teve como escopo discutir como se dá a formação de conceitos científicos e o desenvolvimento da memória de alunos que se encontram no período entre a primeira infância e a adolescência. De acordo com a Psicologia Histórico-Cultural, a formação de conceitos incide diretamente no desenvolvimento do psiquismo humano, e tais processos originam-se das operações intelectuais mediadas pela palavra (signo) e pelo uso de instrumentos físicos.

Nessa direção, a formação dos conceitos espontâneos imediatos se articula à construção dos conceitos científicos, que se edificam mediados pela educação escolar intencional. A práxis ${ }^{1}$, por sua vez, implica o desenvolvimento da conduta humana que auxilia o homem a tomar consciência do devir histórico. Assim, podemos afirmar que a formação de conceitos científicos se origina da educação escolar mediada pela práxis.

Para Vygotski (1996), “[...] tudo aquilo que era a princípio exterior - convicções, interesses, concepção de mundo, normas, éticas, regras de conduta, tendências, ideais, determinados esquemas de pensamento - passa a ser interior" (VYGOTSKI, 1996, p. 63) devido ao pensamento por conceitos. Esse teórico, a partir da curiosidade de descobrir a origem do processo de desenvolvimento da criança, buscou compreender a formação dos conceitos cotidianos e dos científicos. Por isso, em seus estudos, afirma que a "zona de desenvolvimento iminente" considera o que a criança realiza com a mediação do adulto e a "zona de desenvolvimento real" considera as atividades realizadas pela criança sem auxílio do outro.

Vygotski (2012) esclarece que o processo de domínio da memória acontece por meio das operações e da generalização das palavras, o que envolve a imaginação, a comparação e a construção de novas conexões, ou seja, o desenvolvimento das "Funções Psicológicas Superiores" (FPS), que se relacionam com o desenvolvimento da memorização simples para sua forma mais complexa.

$\mathrm{Na}$ idade pré-escolar, a memória, que até então era subordinada à atividade da percepção, aparece no centro do desenvolvimento, ao passo que a percepção recua para a periferia. Isso quer dizer que, nessa idade, a percepção torna-se subordinada à memória. A percepção, ao ocupar o centro do desenvolvimento, destaca-se do todo da consciência ainda indiferenciada, sem um sistema organizado. A memória, por sua vez, terá o trabalho de ressubordinar as outras funções

\footnotetext{
${ }^{1}$ As primeiras noções de práxis surgiram com Aristóteles, mas foi Karl Marx o responsável pelo aprofundamento dessa concepção. Práxis é um conceito básico da filosofia marxista, que remete à transformação material da realidade. Segundo Aristóteles, a práxis é o fundamento da teoria, mas, para Marx, a teoria deve estar incluída na práxis. De acordo com a visão de Karl Marx, a práxis remete aos instrumentos em ação que determinam a transformação das estruturas sociais. Esse autor utilizou o conceito de práxis como uma crítica ao idealismo e ao materialismo.
} 
que já eram subordinadas à percepção. Por isso, é correto ressaltar que o papel da memória no trâmite do desenvolvimento é um pouco mais árduo. Como ressaltam Prestes e Tunes (2018), “a primeira novidade com a qual nos deparamos é que a nova função, por assim dizer, tem um concorrente potente, um rival competente. Ela deve ocupar não um lugar vazio, como foi com a percepção, mas reestruturar um sistema que já se constituiu” (PRESTES; TUNES, 2018, p. 107).

A função da memória é reestruturar o sistema, ao passo que a percepção faz surgir o sistema. É importante entender que a nova função se deslocou do segundo plano para o centro do desenvolvimento da consciência com auxílio da primeira função, em que uma se apoia na outra. É como uma alavanca que impulsiona o desenvolvimento para situações mais elaboradas, pois, tanto na idade pré-escolar quanto nas posteriores, aumenta-se a complexidade do desenvolvimento das funções. É na adolescência, contudo, que o processo de internalização das funções complexas apresenta o auge do desenvolvimento como categoria intrapsíquica.

Com base nessas considerações inicias, este estudo reconhece que, para a formação dos conceitos científicos e o desenvolvimento da memória, a prática pedagógica do professor deve estar amparada por pressupostos epistemológicos que articulem teoria e prática, resultando em um efetivo processo de ensino e aprendizagem. Em vista disso, o objetivo desta investigação foi discutir a formação dos conceitos científicos e o desenvolvimento da memória de alunos entre a primeira infância e a adolescência e analisar se Referencial Curricular do Paraná: princípios, direitos e orientações (PARANÁ, 2018), elaborado a partir da Base Nacional Comum Curricular - BNCC (BRASIL, 2017) contempla tais conceitos.

Para apresentar os resultados desta investigação teórica e documental, este texto foi assim organizado: esta introdução, que contextualiza o tema e os objetivos; posteriormente, discutimos como são formados os conceitos cotidianos e os científicos; na sequência, discorremos sobre a ressignificação das práticas docentes que auxiliam o desenvolvimento da memória, analisando o Referencial Curricular do Paraná (2018); por fim, tecemos as últimas considerações.

\section{Conceitos cotidianos e conceitos científicos}

$\mathrm{Na}$ adolescência, o processo de internalização das FPS apresenta o auge do desenvolvimento como categoria intrapsíquica. O pensamento do adolescente altera-se no conteúdo e na forma, um fenômeno sem precedentes no desenvolvimento infantil. O pensamento conceitual possibilita ao adolescente conhecer a realidade, interna e externa, para além de sua aparência, abarcando as múltiplas determinações. 
O referido processo inicia-se na infância e vai se desenvolvendo até a adolescência. A criança, em tenra-idade, pronuncia as palavras ditas pelo adulto, contudo, não ultrapassa o domínio da verbalização. Esse processo, no entanto, é fundamental, pois, por meio da mediação, a criança se apropria, historicamente e culturalmente, dos signos, enquanto espera-se que o adulto já os domine.

O verdadeiro conceito está ligado à capacidade de análise e de síntese. Segundo Vigotsky (2010), o adolescente, a partir de 12 anos, já desenvolveu suas FPS a ponto de iniciar a construção dos conceitos científicos. Esses não são construídos de forma atomística, por meio de processos naturais e espontâneos. Desse modo, considerando a importância do processo de formação de conceitos para o desenvolvimento psicológico do sujeito, é necessário compreendermos as diferenças na origem e no desenvolvimento dos conceitos espontâneos e científicos, os quais dependem um do outro, posto que

[...] sua origem, sua estrutura psicológica e suas funções, ambos são deveras próximos,
pois uma criança adquire um conceito científico quando houver certo desenvolvimento
de um conceito espontâneo pertinente. Logo, explica-se porque a criança muito pequena
demora a apropriar-se de conceitos espaciais - como perto, longe - ou de tempo - tais
como ontem, hoje e amanhã - pois primeiro deve desenvolver conceitos cotidianos,
como aqui, lá, agora, depois. (COSTAS, 2003, p. 105).

Os conceitos espontâneos são determinados no cotidiano, na comunicação da criança com seus pares e também com outras pessoas. Eles "são organizados em um conjunto de relações nem sempre conscientes e sistematizadas. Portanto, a criança dificilmente consegue explicar o que entende por um conceito cotidiano" (ASBAHR, 2017, p. 183). Esse tipo de conceito é mediado por uma atividade de caráter consciente e intencional, sendo que os conceitos científicos têm como base espontâneos, que são reconfigurados à medida que os conceitos científicos são apreendidos.

A concepção de mundo, os traços de personalidade e o controle da conduta não iniciam na adolescência, mas em processos anteriores. Entretanto, a educação escolar é responsável pela formação dos conceitos científicos. Assim, de acordo com Costas (2003),

[...] acrescenta-se a função potencial da escola formal na construção dos conceitos científicos, mais especificamente dos conteúdos disciplinares. Inserindo-se como parte integrante dos conceitos científicos, os conceitos formais modificam paulatinamente a estrutura dos conceitos espontâneos, transformando-os em sistemas, o que resulta em elevação do grau de desenvolvimento infantil e, por fim, na inserção gradual da criança no pensamento científico do mundo adulto. (COSTAS, 2003, p. 106). 
Prestes (2012), baseada em Vigotski, explica que,

[...] é exatamente ao desenvolver seus estudos sobre a formação de conceitos na infância que Vigotski chega ao conceito de zona blijaichego razvitia ${ }^{2}$ [...] Vigotski conclui que o grau de domínio dos conceitos cotidianos demonstra o nível de desenvolvimento atual da criança; e o grau de domínio dos conceitos científicos demonstra a zona blijaichego razvitia. (PRESTES, 2012, p. 188-189).

A essência da "zona de desenvolvimento iminente" é a possibilidade de desenvolvimento, considerando que, se a criança não tiver a oportunidade de ter ao seu lado pessoas que colaborem com o seu desenvolvimento psíquico em determinadas etapas da vida, poderá não madurecer algumas funções intelectuais. Todavia, mesmo com essas pessoas ao seu lado, isso não quer dizer o processo de maturidade está garantido, pois ela não atinge a maturação por si só.

Segundo Vigotsky (2010), a evolução que resulta no desenvolvimento dos conceitos apresenta-se em três estágios: primeiro estágio - "pensamento sincrético"; segundo estágio "pensamento por complexos"; terceiro estágio - "pensamento por conceitos".

No estágio do "pensamento sincrético", a criança forma amontoados de objetos sem nenhuma relação. Esses se aproximam de um significado comum, não por força do seu próprio traço, mas por meio da semelhança que a criança estabelece a partir de suas impressões. Nessa perspectiva, "a criança encontra-se, frequentemente, no significado das suas palavras com os adultos, ou melhor, o significado da mesma palavra na criança e no adulto se cruza com frequência no mesmo objeto concreto e isso é suficiente para que adultos e crianças se entendam" (VIGOTSKY, 2010, p. 176). Entretanto, são bem diferentes os caminhos que levam ao cruzamento do pensamento do adulto e o da criança. O significado da palavra infantil coincide, parcialmente, com o significado da palavra adulta. Isso decorre psicologicamente de operações bem diversas e originais; é produto da mistura sincrética de imagens que estão por trás das palavras da criança.

O "pensamento sincrético" divide-se em três fases: a primeira vem ao encontro da formação da imagem sincrética, em que criança escolhe os objetos aleatoriamente. A segunda fase explica que a criança ainda não estabeleceu vínculos entre um objeto e outro. Aparecem os primeiros sinais de organização no campo da percepção. Entretanto,

[...] essa organização se limita a fatores acidentais que exerçam alguma influência imediata sobre a percepção da criança, como a contiguidade espacial e temporal ou mero contato físico. "Nessa etapa, o importante é que a criança continua sendo regida não pelas relações objetivas implícitas nas coisas, mas sim pelas conexões subjetivas criadas por sua própria percepção.” (VYGOTSKI, 2001, p. 136). (ANJOS; DUARTE, 2017, p. 208).

\footnotetext{
${ }^{2}$ Zona blijaichego razvitia quer dizer "zona de desenvolvimento iminente".
} 
Os agrupamentos continuam sincréticos, quer dizer, a criança já considera uma aproximação temporal e espacial entre seus elementos.

$\mathrm{Na}$ terceira e última fase do "pensamento sincrético", a imagem sincrética forma-se em uma base mais complexa, mas ainda não foi superada a visão da desordenação de representação. Vigotsky (2010) pontua que "primeiro formam-se os grupos sincréticos, de onde representantes particulares se separam para tomar a reunificar-se sincreticamente" (VIGOTSKY, 2010, p. 177). Agora, por trás da palavra infantil já não se esconde o plano, mas a perspectiva, a dupla série de vínculos e a dupla reestruturação dos grupos, as quais ainda não se sobrepõem à formação da pluralidade desordenada ou do amontoado.

O pensamento por complexo é o segundo estágio apresentado por Vigotski na evolução do desenvolvimento por conceito. Esse tipo de pensamento se desdobra desde o término da primeira infância até o início da adolescência. As ligações entre seus componentes são concretas e factuais, e a divergência entre um complexo e um conceito diz respeito ao fato de o conceito agrupar os objetos de acordo com um atributo, ao passo que os elementos que unem um complexo ao todo podem ser diversos. Isso significa

[...] que cada objeto particular, abrangido por um conceito generalizado, insere-se nessa generalização na mesma base de identidade com todos os outros objetos. Todos os elementos estão vinculados a uma totalidade expressa em conceitos e, através desse conceito, estão ligados entre si, e ligados, do mesmo modo, por um vínculo do mesmo tipo. [...] No complexo, esses vínculos podem ser tão diversificados quanto o contato diversamente fatual e a semelhança fatual dos mais diversos objetos, que estão em relação lógica e concreta entre si. (VIGO'TSKY, 2010, p. 181).

O pensamento por complexo direciona seus vínculos ao objeto em uma base concreta e fortuita, enquanto o conceito mantém um vínculo uniforme que permite a generalização entre os objetos.

O autor apresenta cinco fases básicas de sistema complexo, que fundamentam as generalizações que aparecem no pensamento da criança. Na primeira fase, apresenta-se o tipo de "complexo associativo". Segundo Anjos e Duarte (2017), “a criança, ao nomear um objeto, expressa o nome de família, ou seja, denominar o objeto concreto com o nome correspondente significa incluí-lo em um determinado complexo concreto com o qual guarda relação" (ANJOS; DUARTE, 2017, p. 209). Nesse complexo, as conexões entre elementos isolados são formadas por meio de elementos comuns, os quais instituem o núcleo do complexo.

O "complexo por coleção" é a segunda fase, qualificada pela generalização. De acordo com Anjos e Duarte (2017), ela se “embasa na afinidade funcional entre os diferentes objetos. [...] O 
complexo por coleção tem como base de conexões a relações entre os objetos presentes na ação prática e na experiência visual da criança” (ANJOS; DUARTE, 2017, p. 210).

Esse complexo se dá por meio da generalização de coisas em conformidade com algum atributo funcional relevante na prática da criança, sendo que ela pode construir tal complexo também em seu pensamento verbal, reunindo em grupos objetos concretos de acordo com a funcionalidade de cada um.

A terceira fase é o “complexo por cadeia”, que se constrói, segundo Anjos e Duarte (2017), "na base da união dinâmica e sequencial de elaborações individuais em uma única cadeia de elementos e a partir da transferência de significados por meio de vínculos ali existentes” (ANJOS; DUARTE, 2017, p. 210).

Vigotsky (2010) menciona que

a criança escolhe para uma determinada amostra um ou vários objetos associados em algum sentido; depois continua a reunir os objetos concretos em um complexo único, já orientada por algum traço secundário do objeto anteriormente escolhido, traço esse que está totalmente fora da amostra. (VIGOTSKY, 2010, p. 185).

Com base nas palavras do autor, compreendemos que o processo de formação do complexo de cadeia incide, o tempo todo, na passagem de um traço a outro, mas o caráter do vínculo pode ser muito diferente. O teórico afirma que o centro estrutural pode estar ausente, por isso, pode não ter nada em comum com os outros elementos, mas, mesmo assim, pertencer a um complexo por ter um traço comum com qualquer outro elemento que, por sua vez, está vinculado a um terceiro e assim por diante. Nessa perspectiva, o pensador conclui: “[...] estamos autorizados a considerar o complexo em cadeia como a modalidade mais pura do pensamento por complexo, pois esse complexo é desprovido de qualquer centro, diferentemente do complexo associativo em que existe um centro a ser preenchido pela amostra [...]” (VIGOTSKY, 2010, p. 187).

O final da cadeia não necessita de vínculos para que os objetos pertençam a um complexo, basta que os elementos estejam aglutinados. Nesse complexo, o centro estrutural pode não aparecer, com isso, não necessariamente terá algo em comum com os outros elementos, mas, devido aos traços em comum, pode pertencer ao mesmo complexo.

O quarto tipo de pensamento é denominado de "pensamento difuso", com características próprias à sua etapa. O pensamento por complexo difuso se dilui nos vínculos indefinidos. Nessa fase, o pensamento se caracteriza por generalizações que a criança é capaz de criar não no âmbito das atividades práticas, porém, ainda são generalizações difusas, pois a lógica do pensamento ainda se encontra nos traços concretos. Para Vigotsky (2010), 
Aqui a criança ingressa em um mundo de generalizações difusas, onde os traços escorregam e oscilam, transformando-se imperceptivelmente uns nos outros. Aqui não há contornos sólidos, e reinam os processos ilimitados que frequentemente impressionam pela universalidade dos vínculos que combinam. (VIGOTSKY, 2010, p. 189).

Os vínculos fundamentam-se em traços indefinidos, ou seja, os complexos difusos são as generalizações no campo do pensamento que não dependem da verificação prática, nesse caso, a criança começa a raciocinar para além disso.

O "pseudoconceito" é a quinta fase do pensamento por complexo. Nele, a criança assimila o domínio de termos de conceitos empregado pelos adultos, apresenta a generalização do conceito, mas ainda não superou o concreto. Esse aspecto é assim explicado por Anjos e Duarte (2017):

\begin{abstract}
A lógica interna dos "pseudoconceitos" ainda reside nos traços concretos do objeto, pois as generalizações que existem não ultrapassam a fusão com os objetos reais aos quais a criança tem acesso. O domínio da abstração, que tem início na adolescência, permite a passagem para a formação dos conceitos propriamente ditos. Para Vigotski, os conceitos só aparecem quando os traços são sintetizados novamente e a síntese abstrata resultante transforma-se no principal instrumento do pensamento. (ANJOS; DUARTE, 2017, p. 211).
\end{abstract}

Nesse contexto, o pensamento abstrato depende da relação do adulto com a criança. O modo impositivo da comunicação entre ambos não desconstrói a atitude ativa do pensamento da criança. Sabemos que essa relação é construída por intermédio da palavra na vivência do adulto com a criança, que não cria significados aleatoriamente, já que são mediados pelo outro. A mediação que alavanca a construção dos significados se dá também por meio da interação da criança com outra criança com mais experiência, por meio dos veículos de comunicação e também de outros objetos que a circundam. Ressaltamos que os significados construídos na esfera cotidiana são transformados em conceitos científicos na escola, já que a educação escolar é a responsável pela construção do pensamento abstrato.

Algo importante e que deve ser considerado com cuidado é o fato de que a pronúncia de palavras abstratas pela criança não significa que ela já tenha se apropriado dos conceitos, mas simplesmente usa o reportório do adulto. "Essa forma mascarada do 'pensamento por complexos' decorre da semelhança fenotípica entre o ‘pseudoconceito’ e o verdadeiro conceito, é um obstáculo gravíssimo no caminho da análise genética do pensamento” (VIGOTSKY, 2010, p. 194).

É difícil a análise que aponta para divergência entre "pseudoconceito" e o conceito verdadeiramente dito. Contudo, existem grandes afinidades entre eles, pois o pensamento da criança e do adulto somente converge na prática do significado das palavras. 
Sabemos que a adolescência é o período propício para a formação dos conceitos, em que há um salto em direção ao pensamento abstrato. Entretanto, não devemos desconsiderar a importância da educação infantil, que é a gênese do desenvolvimento dos processos psíquicos. Ela fundamenta a estrutura da abstração do pensamento, com destaque às atividades guia e de estudos no processo de formação dos conceitos.

Anjos e Duarte (2017) explica que, para Vigotski, “os conceitos científicos, aos serem ensinados às crianças através da educação escolar, superam por incorporação os conceitos cotidianos, ao mesmo tempo em que a aprendizagem daqueles ocorre sobre a base da formação destes" (ANJOS; DUARTE, 2017, p. 213).

Vigotski analisou a formação dos dois conceitos, o cotidiano e científico, ressaltando que os cotidianos são formados no dia a dia, na vivência prática da criança, já os científicos desenvolvem-se por meio da educação escolar.

A apropriação pelo adolescente do conhecimento erudito e clássico aponta para a possibilidade de superação dos conceitos cotidianos, que são a base para a constituição dos conceitos científicos. Essa superação não é oriunda da espontaneidade no nível do “pseudoconceito". Essa afirmação dá autenticidade à importância da educação escolar em todos os níveis de escolarização, pois um depende do outro para atingir o nível do pensamento abstrato na adolescência. Diante disso, a educação escolar, desde a pré-escola, deve trabalhar conteúdos que venham ao encontro do desenvolvimento das "Funções Psicológicas Superiores", e os jogos e as brincadeiras apresentam uma função principal na promoção de possibilidades que fundamentam o psíquico da criança para os futuros desenvolvimentos. Em outras palavras, os conceitos cotidianos são a base para a construção dos conceitos científicos.

Anjos e Duarte (2017) explicam que, para Menchinscaia (1960), os conceitos que se formam fora da educação escolar são vulgares ou comuns. O conteúdo desses conceitos não compreende o essencial dos objetos, e o fundamental não está suficientemente delimitado do secundário, ou seja, a essência e a aparência dos fenômenos coincidem-se.

O efetivo domínio do conceito científico não decorre espontaneamente do "pensamento por complexos", mas exige que o trabalho escolar atue sobre aquilo que está germinando na criança no início de e sua escolarização, em que atua sobre a "zona de desenvolvimento iminente”. Nesse sentido, "Os conceitos científicos são frutos do que a ciência legitimou e correspondem às leis objetivas descobertas pelo gênero humano ao longo do processo sócio-histórico" (ANJOS; DUARTE, 2017, p. 214). A autora assevera a importância do trabalho educativo, visto que, somente por meio dele, o adolescente se apropria dos conceitos científicos propriamente ditos. 
A escola, nessa perspectiva, precisa libertar-se das demandas imediatas do cotidiano da sociedade capitalista, que insiste em um processo de existência alienada, haja vista que os conceitos cotidianos não são necessariamente alienados, mas o processo que impede a evolução desse conceito legitima a alienação. O currículo escolar necessita contemplar conteúdos que fomentem à formação científica do adolescente, com objetivo de romper com a alienação intrínseca ao ambiente escolar.

\section{Ressignificando as práticas docentes que auxiliam o desenvolvimento da memória}

A psicologia tradicional, de acordo com Vygotski (2012), considera o processo de desenvolvimento da memória como sendo desenvolvido genuinamente pelas vias orgânicas. Ele cita E. Hering ${ }^{3}$, para quem a memória é propriedade fundamental de toda matéria organizada. A plasticidade da substância nervosa do cérebro manifesta sua capacidade de modificação por meio de estímulos externos, pois mantém a predisposição desses, desde que sejam repetidos. "Este hecho ha permitido comparar figuradamente la memorización con la apertura de vías nerviosas que parecen las rodadas dejadas por el movimiento de las ruedas en el camino o el pliegue que se forma en el papel cuando se dobla" (VYGOTSKI, 2012, p. 247) ${ }^{4}$.

Nosso cérebro, na ótica do psicólogo russo, conserva nossa experiência anterior e promove a sua reprodução. No entanto, a atividade da memória não se resume somente a função. Para além dessa atividade reprodutiva, notamos no comportamento humano outro gênero de atividade, a atividade criadora na qual a imaginação se edifica buscando resquícios das experiências conservadas na memória para combinar e reelaborar novas situações e um novo comportamento.

Por volta de 1920, a memória era compreendida como habilidade mental e seu desenvolvimento era discutido no âmbito biológico. O cérebro cumpria a função de registrar informações que viriam à tona por meio de um processo automático (mecânico). Entre os anos de 1920 e 1930, Lúria e Vigotski, imbuídos pela psicologia russa, iniciaram os estudos e as discussões sobre o desenvolvimento da memória a partir da história social da humanidade, considerando os aspectos da cultura.

Todavia, Vygotski (2012) considerou que o estudo teórico da época não dava conta de distinguir a memória técnica "mnemotécnica" da memória "mnemônica" (mneme). A "mnemotécnica", em seu verdadeiro e fiel princípio, conduz todo o processo de desenvolvimento cultural da memória. Assim, os teóricos distinguiam-nas como memórias de representação do

\footnotetext{
${ }^{3}$ E. Hering considerava, por exemplo, a memória uma "propriedade universal da matéria".

4 "Este fato nos permitiu comparar figurativamente a memorização com a abertura de caminhos nervosos que se parecem com as marcas deixadas pelo movimento das rodas no caminho ou a dobra que se forma no papel quando se dobra" (VYGOTSKI, 2012, p. 247, tradução nossa).
} 
pensamento: “[...] mnemotécnica se comprendan todos los procedimientos de memorización que incluyan la utilización de ciertos medios técnicos externos y están dirigidos a dominar la propia memoria" (VYGOTSKI, 2012, p. 248) 5. As concepções de “mneme” e "mnemotécnicas" eram termos utilizados há tempos na psicologia, mas apresentavam significados diferentes. Os demais psicólogos da época não conseguiram o discernimento suficiente para compreender "mnemotécnica" como sendo os processos culturais de memorização e "mneme" como os processos orgânicos.

Vygotski (2012) explica que Bergson ${ }^{6}$, em seu famoso estudo sobre a matéria e a memória, chegou à conclusão de que a memória se formava em dois momentos: pelas lembranças impressas no cérebro e pelo espírito. Ao dar ênfase à explicação, Vygotski (2012) ressalta que S. Freud "dedujo asimismo que la actividad de nuestra memoria sólo puede explicarse si admitimos que está formada por dos partes integrantes del sistema separadas y unidas simultáneamente entre sî" (VYGOTKSKI, 2012, p. 248) ${ }^{7}$. Diante de toda essa problemática relacionada à formação da memória, Vigotski se propôs a realizar uma investigação científica com crianças na idade infantil, a fim de delimitar a distinção entre os dois tipos de memórias. A justificativa para isso se deu por não concordar com as posições de Bergson e Freud a respeito do desenvolvimento dessa função psíquica.

O autor, em sua investigação ${ }^{8}$ a respeito do processo de memorização, sugeriu que às crianças memorizassem vários substantivos e nomes de objetos concretos. Sua observação partia da não possibilidade de memorização de todos os nomes organizados em uma ordem. Diante da não possibilidade da memorização, substituiu a experiência, oferecendo uma nova forma de memorizar. Dessa vez, apresentou-lhes o conteúdo da memorização em cartões já dispostos para tal experimento, que continham desenhos de objetos concretos e desenhos com vários traços (geométricos, lineares, com listras etc.).

Ademais, utilizou-se de outros experimentos, porém, sempre apresentando à criança os cartões com os desenhos e as palavras. No entanto, a investigação sobre a formação da memória foi muito além do fato da memorização, pois observou o curso das conexões nervosas e a formação de novas estruturas. Isso quer dizer que somente o processo de memorização, por associação

\footnotetext{
5"Compreende-se "mnemotécnica" todos os procedimentos de memorização que incluem o uso de certos meios técnicos externos e são utilizados e são utilizados para dominar a própria memória” (VYGOTSKI, 2012, p. 248, tradução nossa).

${ }^{6}$ H. Bergon (1859-1941) foi crítico do pensamento dogmático, estudou o movimento criativo como elemento fundamental na experiência de vida consciente.

7“"Deduzo que a atividade da nossa memória só pode ser explicada se admitirmos que ela é formada de duas partes do sistema e simultaneamente separadas e ligadas entre si” (VYGOTSKI, 2012, p. 248, tradução nossa).

${ }^{8}$ Vigotski confronta, em suas investigações experimentais psicológicas, ambos os tipos de memória.
} 
esquemática, desenho/signos, não daria conta da complexidade representada pela realidade, da qual participam vários estímulos.

O autor exemplifica da seguinte forma:

[...] cuando al oír la palabra "muerte" el niño elige el dibujo "camello", crea la siguiente estructura: "El camello está en el desierto, el viajero muere de sed". Desde el punto de vista de la psicología asociacionista sería del todo imposible explicar por qué se memorizan más fácilmente y con mayor solidez estructuras relativamente más complejas que la simple conexión asociativa entre dos elementos. (VYGOTSKI, 2012, p. 250)9 .

É possível compreender que as conexões antigas servem de base para a formação de novas conexões, no momento em que a criança associa a palavra morte ao desenho do camelo, fazendo relação com alguma história já ouvida sobre o deserto. Nesse momento, os experimentos demonstram que somente as bases associativas e as conexões antigas não são suficientes para explicar a memorização, uma vez que, como ressalta Vygotski (2012), a criança, na maioria das vezes, cria estruturas completamente novas e não restabelece as antigas.

Por isso, no primeiro momento, quando a criança ouviu a palavra morte e a associou ao camelo e ao viajante no deserto, ela reviveu uma história ouvida muitas vezes. No segundo momento, ela relacionou as palavras caranguejo e teatro com a intenção de memorizar a palavra teatro. Desse modo, seria muito difícil o ponto de vista associativo explicar que uma representação tão complexa se memoriza com mais facilidade do que um simples nexo associativo.

O experimento demonstrou que os desenhos apresentados faziam com que as crianças se recordassem das palavras, elegendo apenas as velhas estruturas. Assim, Vigotski atentou-se para o significado paradoxal do pensamento, pois, a partir do momento que se apresenta o desenho para a criança se lembrar da palavra, não se criam novas estruturas. Altera-se radicalmente essa situação quando a criança se nega a eleger o desenho para recordar as palavras, no sentido de que é impossível memorizar todas as palavras de acordo com os desenhos apresentados. Dessa maneira, a criança percorre o caminho da criação de novas estruturas, construindo o processo do domínio da memória. O autor afirma que, do ponto de vista psicológico, a experiência não estuda a memória, mas sim a criação ativa das estruturas.

No entanto, cada criança segue caminhos completamente distintos para alcançar o resultado. Por exemplo, no primeiro momento do experimento, apresentava-se à criança o cartão

\footnotetext{
${ }^{9}$ Quando a criança escolhe o desenho "camelo" ao ouvir a palavra "morte" cria a seguinte estrutura: "O camelo está no deserto, o viajante morre de sede". Do ponto de vista da psicologia associacionista, seria bastante impossível porque estruturas relativamente mais complexas são memorizadas com mais facilidade do que a simples conexão associativa entre dois elementos. (VYGOTSKI, 2012, p. 248, tradução nossa).
} 
com o desenho sem nenhuma orientação de como poderia ocorrer o processo de memorização, somente solicitava-se que ela memorizasse o desenho, realizando a atividade no sentido mecânico. No segundo momento, o cartão com o desenho foi apresentado de maneira diferente: o condutor do experimento explicava-lhe, com detalhes, que deveria relacionar o desenho a algumas palavras, inclusive oferecia exemplos. A criança compreendia o processo, relacionando o desenho à palavra e, por conseguinte, explicava a relação estabelecida entre a palavra e o desenho. Assim, a criança passava do processo natural de memorização para a memorização mediada, ou seja, para a formação da memória "mnemotécnica", construindo novas estruturas de formação da memória por meio da comparação, da imaginação, da generalização da palavra (signos).

O processo de memorização necessita ser desenvolvido com atividades que busquem a generalização dos signos, em um processo de relação entre eles, e não com atividades repetitivas, associativas, que se estabelecem nas bases naturais da memória. Nesse sentido, vemos que,

\begin{abstract}
[...] a base orgânica dessa atividade reprodutiva ou da memória é a plasticidade da nossa substância nervosa. Chama-se plasticidade à propriedade de uma substância que permite alterá-la e conservar as marcas dessa alteração. [...] no cérebro, ocorre algo semelhante ao que acontece a uma flor de papel quando a dobramos ao meio. No local da dobra, fica a marca resultante da modificação feita, bem como a predisposição para repetir essa modificação no futuro. Basta, agora, soprar essa folha de papel para que se dobre no mesmo local em que ficou a marca. (PRESTES; TUNES, 2018, p. 14).
\end{abstract}

No entanto, o cérebro humano não apresenta apenas a finalidade de conservar o já apropriado e reter experiências anteriores, mas reelabora, de maneira criativa, os elementos anteriores adquiridos, emergindo desse processo situações e comportamentos novos. O desenvolvimento da memória não se abrevia à mera reprodução do velho, mas amplia-se no sentido da criação e da reformulação.

Vale ressaltar que a educação escolar, responsável pela formação de conceitos científicos, deve compreender o desenvolvimento do psiquismo humano com relação ao processo do ensino e da aprendizagem, com o intuito de direcionar práticas pedagógicas que amparem o desenvolvimento das FPS.

Nesse sentido, considera-se que a formação continuada do professor, de acordo com o proposto no Referencial Curricular do Paraná - Princípios, Direitos e Orientações (PARANÁ, 2018), não fundamenta, teoricamente, a prática pedagógica no sentido de compreender a formação dos conceitos científicos e o desenvolvimento da memória. A partir de uma leitura da seção "Saberes e Conhecimentos/Objetivos de Aprendizagem e Desenvolvimento" desse documento, constatamos que ela não sustenta a teoria no tocante ao desenvolvimento da prática. 
Para uma maior compreensão dessa afirmação, exemplificamos com os dois quadros a seguir:

Quadro 1 - Educação infantil

\begin{tabular}{|l|l|l|l|}
\hline $\begin{array}{l}\text { Organizador } \\
\text { Curricular }\end{array}$ & $\begin{array}{l}\text { Campos de } \\
\text { Experiência }\end{array}$ & $\begin{array}{l}\text { Saberes e } \\
\text { Conhecimentos }\end{array}$ & $\begin{array}{l}\text { Objetivos de Aprendizagem e } \\
\text { Desenvolvimento }\end{array}$ \\
\hline $\begin{array}{l}\text { - Crianças pequenas (4 } \\
\text { anos) }\end{array}$ & $\begin{array}{l}\text { - Traços, sons, } \\
\text { cores e forma }\end{array}$ & $\begin{array}{l}\text { - Percepção e } \\
\text { memória auditiva }\end{array}$ & $\begin{array}{l}\text { - Reconhecer as qualidades do som } \\
\text { (intensidade, duração, altura e timbre), } \\
\text { utilizando-as em suas produções sonoras e } \\
\text { ao ouvir músicas e sons; } \\
\text { - Manipular e perceber os sons de } \\
\text { instrumentos sonoros diversos (PARANÁ, } \\
\text { 2018, p. 160). }\end{array}$ \\
\hline $\begin{array}{l}\text { - Crianças pequenas (5 } \\
\text { anos) }\end{array}$ & $\begin{array}{l}\text { - Traços, sons, } \\
\text { cores e formas }\end{array}$ & - Percepção e \\
memória auditiva & $\begin{array}{l}\text { - Escutar e perceber músicas de diversos } \\
\text { estilos musicais, por meio da audição de } \\
\text { CDs, DVDs, rádio, MP3, computador ou } \\
\text { por meio de intérpretes da comunidade } \\
\text { (PARANÁ, 2018, p. 195). }\end{array}$ \\
\hline
\end{tabular}

Fonte: Paraná (2018).

Quadro 2 - Ensino fundamental, $1^{\circ}$ ano, Arte

\begin{tabular}{|l|l|l|}
\hline Unidade temática & Objetos de conhecimentos & Objetivos de Aprendizagem \\
\hline Artes Visuais & Materialidades & $\begin{array}{l}\text { Explorar diferentes tipos de tintas e } \\
\text { materiais pictóricos (industrializados e } \\
\text { artesanais), em diferentes suportes, } \\
\text { para experienciar possibilidades } \\
\text { diversas e perceber efeitos com } \\
\text { relação ao material, tamanho do } \\
\text { suporte, textura e cor, } \\
\text { experimentando as diversas } \\
\text { possibilidades de uso de materiais, } \\
\text { para desenvolver a pesquisa, a } \\
\text { capacidade de observação, a } \\
\text { memória visual, a imaginação } \\
\text { criadora. (PARANÁ, 2018, p. 231). }\end{array}$ \\
& \\
& \\
&
\end{tabular}

Fonte: Paraná (2018).

Com o intuito de ressignificar a prática pedagógica em consonância com os "Objetivos da Aprendizagem e do Desenvolvimento", bem como com os "Saberes e Conhecimentos" (percepção, memória auditiva, memória visual) propostos nos Quadros, entendemos os "Objetivos e Saberes" como uma prática pedagógica corriqueira, desenvolvida na Educação Infantil e no Ensino Fundamental - Anos Iniciais. No entanto, ela é dificilmente articulada à teoria. O professor, ao trabalhar os objetivos de aprendizagem de cada ano e de cada modalidade de 
ensino (descritos no Referencial já citado), deveria compreender em que incide a prática direcionada em cada um dos elementos: Objetivos/Objetos de Conhecimento/Saberes e Conhecimentos.

A percepção e a emoção são funções psicológicas que se isolam do todo da consciência entre a idade de bebê e a primeira infância. A consciência, antes percebida como um campo indiferenciado, divide-se, agora, em centro e periferia. O centro será ocupado pela percepção articulada às emoções. Por volta do terceiro ano de idade, a memória da criança age com auxílio da atividade da percepção, ou seja, a memória é submissa à percepção, a criança só recorda quando visualiza o objeto ou quando reproduz alguma situação vivenciada anteriormente. A memória da criança, desde bebê, não existe por si só, porém, encontra-se completamente indiferenciada, visto que ela ainda age submissa à percepção que, nesse contexto, é que determina toda a atividade consciente.

$\mathrm{Na}$ idade pré-escolar ${ }^{10}$, a percepção deixa de atuar no centro do desenvolvimento psicológico da criança e volta para a periferia. Nessa etapa, quem assume o centro é a função da memória. O que há de novo e relevante na transição das funções é que, na passagem do bebê para primeira infância, não existia um sistema funcional estruturado na consciência e as funções destacam-se pela primeira vez, no sentido de dominá-la. Por outro lado, a passagem para a idade pré-escolar apresenta um sistema, que implica uma passagem complexa, dado que, anteriormente, a consciência encontrava-se em um contexto indiferenciado.

Ressaltamos que não são todas as funções que cumprem com o trajeto (centro - periferia e vice-versa), já que, na idade pré-escolar, somente a memória se destaca. Tal função, antes subordinada pela percepção, agora precisa ressubordinar a si as outras funções; isso significa uma reestruturação do sistema. A memória não ocupa o lugar da percepção, é o sistema antigo que se reestrutura de tal modo que a percepção passa a ser subordinada pela memória.

$\mathrm{Na}$ idade escolar, as funções se desenvolvem em grau maior de complexidade e cada vez mais nas idades futuras. Assim, surge uma característica importante do desenvolvimento das funções: nem todas devem passar pela função de dominante, pois a ressubordinação indica uma nova direção no processo da diferenciação das funções, que são permeadas pelas relações interfuncionais.

Vygotski (2012) afirma que o processo de domínio da memória recorre a operações da generalização das palavras, o que envolve a imaginação, a comparação, a construção de novas conexões, ou seja, o desenvolvimento das FPS, que são responsáveis pela evolução da

${ }^{10}$ A idade pré-escolar, de acordo com Vigotski (2018), seria a criança acima de 3 e até 6 ou 7 anos. 
memorização simples para sua forma mais complexa. O processo natural da memória é vencido pela internalização dos signos que, generalizados e mediados pela cultura, transformam a memória imediata em memória volitiva, quer dizer, na memorização fundamentada em funções intelectuais e não orgânicas.

Percorre-se o caminho supracitado na tentativa de explicar que o Referencial Curricular do Paraná, que foi implantado em todo o Estado (nas instâncias públicas - estaduais e municipais - e privadas) com a finalidade de direcionar o trabalho pedagógico na Educação Infantil e no Ensino Fundamental - Anos Iniciais e Finais, em nenhum momento, aborda os "Objetivos" e os "Conhecimentos" no âmbito teórico.

Entendemos que o professor, para desenvolver a sua prática pedagógica e direcionada à percepção e à memória, necessita de fundamentação científica para compreender, no processo de ensino e aprendizagem, o desenvolvimento dessas funções e a construção da consciência, do contrário, o ensino e a aprendizagem escolar não alavancarão o nível da construção do pensamento por conceitos científicos, cujas bases estão arraigadas ao desenvolvimento das FPS, que nem mesmo são mencionadas pelo Referencial Curricular.

As atividades apresentadas a seguir nas Figuras 1 e 2 não contemplam o desenvolvimento da memória no ápice de sua função, mas tais exercícios apenas reforçam a construção da memória orgânica. 
Figura 1 - Atividades escolares

PINTE SEGUINDO AS CORES

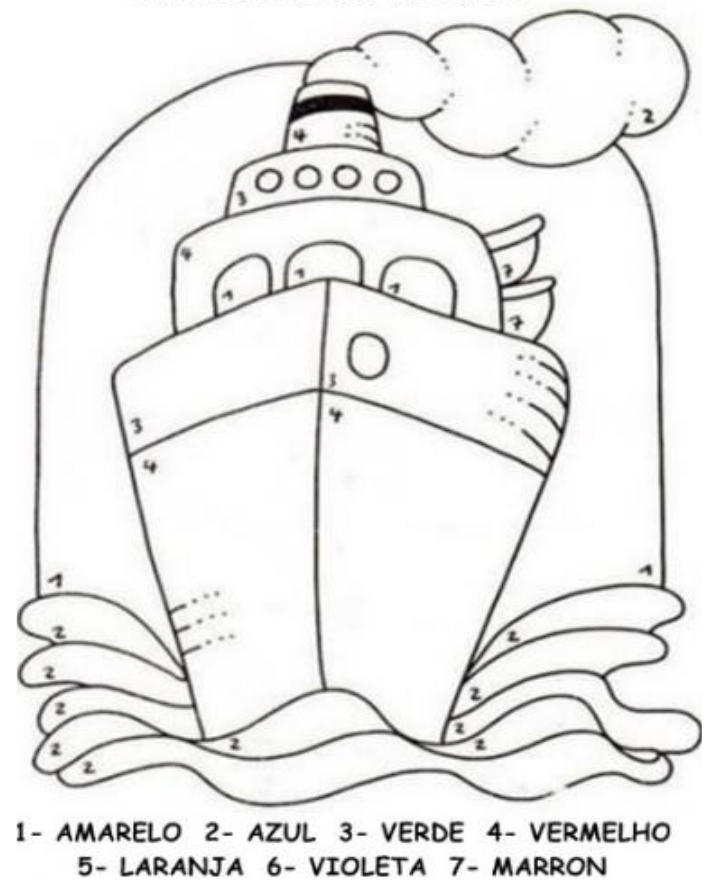

Figura 2 - Atividades escolares

\begin{tabular}{|c|c|c|c|}
\hline \multicolumn{4}{|c|}{$\begin{array}{l}\text { RECORTE AS PALAVRAS DAS FICHAS E } \\
\text { COLE-AS, DEACORDO COM OS DESENHOS. }\end{array}$} \\
\hline & 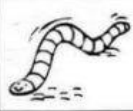 & & $\underbrace{}_{-1 / 3}$ \\
\hline & & 题 & 茴 \\
\hline & & & \\
\hline & & 踥解 & \\
\hline PIRANHA & MINHOCA & PAMONHA & GALINHA \\
\hline LENHA & NINHO & ARANHA & LINHA \\
\hline RAINHA & PINHEIRO & FARINHA & DINHEIRO \\
\hline VINHO & CEGONHA & CAMINHĀO & SARDINHA \\
\hline
\end{tabular}

Fonte: $B \& F(20$ ?).

A memória orgânica é o alicerce para o desenvolvimento da formação da memória complexa, no entanto, as atividades de completar a história e o desenho, pintar de acordo com o modelo, recortar a palavra e colar sobre o desenho são exercícios que não vêm ao encontro do desenvolvimento da memória "mnemotécnica".

As atividades escolares desenvolvidas nos aspectos da memorização mecânica por meio do ato associativo não constroem a estrutura complexa que sustenta o desenvolvimento da memória cultural.

\section{Considerações Finais}

Diante deste estudo, podemos dizer que a educação em suas diferentes modalidades de ensino vem se desenhando em um contexto contraditório, fragilizado, de conflitos das mais diferentes naturezas. Consequentemente, isso se reflete no processo ensino e aprendizagem.

Foi possível compreender que a teoria desarticulada da prática pedagógica dificulta o processo de formação de conceitos científicos, bem como o desenvolvimento da memória. Tais processos necessitam que a teoria e a prática caminhem juntas, ou seja, o professor, no desenvolvimento da prática fundamentada no senso comum, não trabalha o conteúdo de modo intencional. O conteúdo mediado pelo professor necessita ir além daquilo que o aluno já sabe. 
Ressalta-se a necessidade de o professor conhecer o desenvolvimento do psiquismo humano relacionado ao processo de aprendizagem, bem como quais conteúdos trabalhar, de que forma e quando trabalhá-los, a fim de atingir o processo de formação de conceitos. Isso requer que se compreenda que o processo de desenvolvimento se estabelece em dois níveis: a "zona de desenvolvimento real" e a "zona de desenvolvimento iminente".

Dessa maneira, o professor deve proporcionar condições ao adolescente para ultrapassar a formação do pensamento por "pseudoconceitos", permitindo-lhe uma visão crítica do mundo que o circunda. É imprescindível que, atuando em sala de aula, o docente tenha conhecimento de como ocorre o desenvolvimento da memória "mnemotécnica" e a "mnemônica", aspectos relacionados ao desenvolvimento do psiquismo humano e à construção dos conceitos científicos.

Percebemos, ao longo dos anos, que a educação escolar apresenta dificuldades para romper com certas práticas formadas no âmbito da educação sistematizada, primando pelo pragmatismo, pela fragmentação, pelo aligeiramento, ações que comprometem a formação de conceitos científicos e impedem a autonomia do aluno e o processo de humanização do sujeito.

Nesse sentido, concorda-se com Vázquez (2011) que a relação entre teoria e prática se caracteriza como uma relação de oposição, em que a atividade teórica por si só não é práxis. A teoria permanece em seu estado puramente teórico, não se transita dela à práxis. Todavia, a práxis é construção do conhecimento que revoluciona e que transforma. Por isso, a teoria e a prática são elementos opostos, mas que se incluem, uma vez que a práxis se forma a partir da interação de sistemas culturais, históricos e sociais complexos.

Em última instância, o homem se humaniza a partir da práxis, do contrário, e, pensando no campo educativo, o que acontece é a construção de um plano de trabalho docente elaborado pelo professor sem a preocupação ou sem condições de compreender o conteúdo a ser ministrado em função do processo de desenvolvimento e aprendizagem: como e de que maneira tal conteúdo incidirá na transformação das estruturas e das FPS dos alunos.

Diante do exposto, notamos que o professor em sala de aula, especificamente na Educação Infantil e nos Anos Iniciais do Ensino Fundamental, vem desenvolvendo a prática pedagógica sem associá-la à teoria, que sustenta o trabalho pedagógico, ou seja, o trabalho pedagógico não está amparado pela práxis. Sabemos que a ação na prática docente deve considerar a unidade entre a teoria e a prática, e Vázquez (2011), nessa perspectiva, argumenta que "interpreta-se falsamente essa unidade da teoria e da prática quando se nega a autonomia relativa da primeira" (VÁZQUEZ, 2011, p. 260). 
Tal apontamento não se dá no âmbito de uma crítica rasa e descontextualizada ao trabalho docente, mas, de acordo com o estudo realizado sobre o documento do Referencial Curricular do Paraná (2018), comprovamos a não preocupação com a fundamentação teórica sobre a aprendizagem e o desenvolvimento do aluno. Documentos tais como a BNCC (2017) e o Referencial Curricular do Paraná (2018) foram criados para embasar política e teoricamente a prática pedagógica, no entanto, o que temos presenciado é que isso historicamente não tem se efetivado, como procurou-se discutir ao longo deste texto.

Em conclusão, afirmamos que os materiais mencionados orientam somente a prática docente, mas, em nenhum momento, abordam a fundamentação teórica, o porquê do desenvolvimento da prática em relação ao desenvolvimento do psiquismo. Tais documentos versam sobre a prática pedagógica, no entanto, o professor, sem conhecer como se dá o desenvolvimento do psiquismo humano, não compreenderá a prática neles proposta, uma vez que não há uma articulação entre a teoria e a prática, distanciando-se da práxis que efetiva o processo de ensino e aprendizagem.

\section{Referências}

ASBAHR, F. S. F.. Idade Escolar e a Atividade de Estudo: educação, ensino e apropriação dos sistemas conceituais. In: MARTINS, L.M.; ABRANTES, A. A.; FACCI, M. G. D. (orgs.). Periodização Histórico-Cultural do Desenvolvimento do Psíquico: do Nascimento à Velhice. Campinas: Ed. Autores Associados, 2017, p. 171-192.

ANJOS, R. E.; DUARTE, N. O Desenvolvimento da Personalidade na Adolescência e a Educação Escolar: aportes teóricos da psicologia histórico-cultural e da pedagogia históricocrítica. In: MARTINS, L.M.; ABRANTES, A. A.; FACCI, M. G. D. (orgs.). Periodização HistóricoCultural do Desenvolvimento do Psíquico: do Nascimento à Velhice. Campinas: Ed. Autores Associados, 2017, p. 195-219.

BRASIL. Ministério da Educação, Conselho Nacional de Educação. Resolução CNE/CP n 2, de 22 de dezembro de 2017. Institui e Orienta a Implantação da Base Nacional Comum Curricular, a ser Respeitada Obrigatoriamente ao longo das Etapas e Respectivas Modalidades no Âmbito da Educação Básica. Brasília, DF: MEC/CNE, 2017. Disponível em:

http:/ / portal.mec.gov.br/index.php?option $=$ com_docman\&view $=$ download\&alias $=79631$ rcp002-17-pdf\&category_slug=dezembro-2017-pdf\&Itemid=30192. Acesso em: 15 ago. 2021.

COSTAS, F. A. T. O Processo de Formação de Conceitos Científicos em Crianças com Necessidades Educacionais Especiais na $1^{a}$ Série do Ensino Fundamental. 2003. Tese (Doutorado em Educação) Universidade Federal do Rio Grande do Sul, Porto Alegre, 2003.

PARANÁ. Secretaria Estadual de Educação. Referencial Curricular do Paraná: Princípios, Direitos e Orientações. Educação Infantil e Componentes Curriculares do Ensino Fundamental. Curitiba: SEED, 2018. 
PRESTES, Z. Quando não é quase a mesma Coisa. Campinas: Autores Associados, 2012.

PRESTES, Z.; TUNES, E. 7 aulas de L. S. Vigotski sobre os fundamentos da Pedologia. Rio de Janeiro: E-papers, 2018.

VÁZQUEZ, A. S. Filosofia da Práxis. Tradução de Maria Encarnación Moya. 2. ed. São Paulo: Expressão Popular, 2011.

VIGOTSKY, L. S. Obras Escogidas. Tomo IV. Madrid: Visor, 1996.

VIGOTSKY, L. S. A Construção do Pensamento e da Linguagem. Tradução de Paulo Bezerra. São Paulo: Martins Fontes, 2010.

VYGOTSKI, L. S. Obras Escogidas - III Problemas del Desarrollo de la Psique. Tomo III. Madrid: Editora Antonio Machado Libros, 2012.

VIGOTSKI, L. S. Imaginação e criação na Infância. Tradução e revisão técnica: Zoia Prestes e Elizabeth Tunes. 1. ed. São Paulo: Expressão Popular, 2018. 